\title{
IMAGINANDO EL AGUJERO NEGRO
}

\section{Nelsy Niño Rodríguez ${ }^{1}$}

Siento desde mi cuerpo y por eso no disocio lo sensorial de lo corporal. Me enseñaron a sentir con el cuerpo, pero no a pensar como puedo sentir sin la necesidad de corporificar.

Por medio del cuerpo creo, conozco y aprendo, desde y con el cuerpo soy mundo, hago mundo y transito por varios mundos. Con mi cuerpo escucho, veo, huelo, toco y hablo, pero ¿realmente todo lo hago con el cuerpo? ¿cada sentido está atado y premeditado por un 'órgano sensorial'? ¿puedo ver sólo con mis ojos o escuchar sólo desde mis oídos? Aunque las imágenes se piensan como objetos netamente visuales, estas también pueden estar construidas desde otras orillas sensoriales. La imagen puede ser la experiencia, y ser evocada desde un estímulo auditivo, táctil u olfativo.

Alan Lightman es un físico y escritor estadounidense que por medio de sus novelas ha hecho aprehensible un conocimiento que se supone hermético y lejano. El conocimiento científico no es accesible para todos, pero Lightman crea la posibilidad de que lo sea desde su narrativa. Usualmente escribe sobre física, pero también escribe sobre mundos ficticios, mundos posibles y mundos existentes. En uno de sus libros menciona cómo el cuerpo limita el conocimiento de esos mundos:

La ciencia ha expandido enormemente la escala de nuestro cosmos, pero nuestra realidad emocional todavía está limitada por lo que podemos tocar con nuestros cuerpos en el lapso de nuestras vidas (Lightman, 2014: 99).

La ciencia es una de las herramientas para conocer esos mundos posibles; nos permite acércanos hacía aquello que no conocemos, hacerlo comprensible e incluso materializarlo. La ciencia nos ha dado la posibilidad de transitar a través de diversas escalas. Hemos

\footnotetext{
${ }^{1}$ Pontificia Universidad Javeriana, Colômbia. Email: nelsy.nino@javeriana.edu.co
}

ORCID id: https://orcid.org/0000-0002-6069-1320 
conocido mundos micro- y macroscópicos a mayor profundidad gracias a herramientas tecnológicas cada vez más precisas y especializadas. Supimos de la existencia de microorganismos que eran la partícula fundamental y explicativa de varias epidemias, y supimos de galaxias, supernovas y agujeros negros que residían en un espacio que pensábamos contenible.

Los agujeros negros son un ejemplo de lo imaginable; residían en nuestras cabezas porque ciertas ecuaciones habían hecho posibles teorizarlos y probarlos. Sin embargo, se pensaba que ese imaginario no podría ser materia, no podría ser imagen leída desde lo visual, sino sólo desde lo mental. Era una imagen evocada, pero no una materializada. Los agujeros negros tienen una aceleración gravitacional tan fuerte que nada puede escapar a ellos, ninguna onda o partícula, nada en nuestro espacio podría situarse allí. Por más romántica que fuera la idea de conocer algo a lo que nada escapa, queríamos una imagen, algo que nos probara que existían desde lo visual más allá de lo probabilístico o teórico. La luz es tanto onda como partícula, así, ni ella puede aproximarse al agujero negro, ¿cómo ver entonces algo desde la oscuridad? ¿cómo crear una imagen desde el negro absoluto?

La primera imagen de un agujero negro se hizo pública el 10 de abril del 2019 (Imagen 1). Esta imagen llevaba un tiempo en el anonimato y estaba situada en las memorias de ciertos computadores a los que pocos tenían acceso. En abril, el mundo pudo ver esta imagen y en poco tiempo se hizo viral. El agujero negro elegido se sitúa en una galaxia cercana llamada M87; para lograr tomar una imagen de este agujero que dista de 55 millones de años-luz de la tierra, era necesario un telescopio del tamaño del planeta. Esta imagen fue posible gracias a la articulación de un grupo de científicos que crearon un súper telescopio a partir de siete telescopios independientes dispersos por todo el mundo. Los datos de la imagen fueron tomados en el 2017, pero los científicos pasaron dos años reconstruyendo la imagen. Dos años juntando piezas a manera de rompecabezas para elegir entre millones a la imagen más posible, la elección se dio en términos de probabilidad. Un algoritmo gestó y orquestó la selección de una sola imagen para el mundo. Una entre millones fue seleccionada para hacer visible lo que se había planteado como invisible.

Katie Bouman fue la científica que lideró el desarrollo de ese algoritmo, si bien más de 200 personas hacen parte del equipo, Bouman es la dirigente y por eso, la imagen de su cara de asombro cuando observó por primera vez la reconstrucción en su pantalla también 
se convirtió en una imagen icónica y viral (Imagen 2). En una de sus charlas impartidas Bouman (2016) explica la locación y el hallazgo astronómico de este agujero negro:

Si pudiésemos hacer un zoom a través de millones de estrellas, 26.000 años luz hacia el corazón de la espiral de la Vía Láctea, llegaríamos al final a un conglomerado de estrellas, justo en el centro. Escrudiñando a través del polvo galáctico con telescopios infrarrojos, los astrónomos han observado estas estrellas durante más de 16 años. Pero lo más espectacular es lo que no pueden ver. Estas estrellas parecen orbitar en torno a un objeto invisible. Monitoreando el movimiento de estas estrellas, los astrónomos han llegado a la conclusión de que lo único tan pequeño y pesado para causar ese movimiento es un agujero negro supermasivo.

Esas estrellas que veían los astrónomos orbitan en un límite. A este se le conoce como el horizonte de sucesos, y de él, ni la luz puede escapar. Siguiendo esta lógica ¿cómo podría ser posible el oxímoron? ¿cómo ver algo que suponíamos invisible? La imagen del agujero negro no lo muestra en sí mismo. Lo que realmente observamos es ese horizonte de sucesos, un remolino de gas, polvo, estrellas e incluso luz que rodea ese horizonte antes de ser absorbido por el interior para no volver a ser visible. Tenemos una imagen estática en el tiempo que no puede ser reproducible en un futuro. Es una imagen del presente, porque el cúmulo de elementos que colinda en ese horizonte nos permite ver la sombra del agujero negro, un cúmulo que no vuelve a ser posible en el tiempo. Es una imagen del futuro, porque nos permite darle cuerpo a una imagen que no había sido visual, sino que sólo había llegado a nosotros a través de otros canales sensoriales. Pero es también una imagen del pasado, porque todo lo que llega a nuestros ojos desde el universo no es una imagen en tiempo real, sino un fractal de lo que en algún momento fue. Toda imagen del universo es imagen del pasado.

La imagen del agujero negro es un suceso histórico. Sheperd Doeleman es el director del proyecto que hizo posible esa imagen. En una charla comenta que "los agujeros negros son realmente el misterio central de nuestra era, porque ahí es donde el mundo cuántico y el mundo gravitacional se unen. Lo que hay dentro es una singularidad" (Doeleman, 2019). Esta imagen conmocionó al mundo científico, sin embargo, la imagen tuvo una gran recepción en el mundo fuera de la academia. Tan pronto se hizo pública, los principales portales de comunicación, los periódicos y las redes sociales estaban llenas de copias de ella. Entre las muchas respuestas, comentarios y alusiones a la imagen, una en particular 
llamó mi atención. La escritora colombiana Carolina Sanín (2019) hizo el siguiente comunicado en su cuenta de Twitter:

\begin{abstract}
Ver esa portentosa foto del agujero negro y leer sobre su dimensión me acuerda de la experiencia del infinito (y del abismo) que uno tiene al leer las "Mil y una noches". Momento de recordar que la ciencia y el arte alcanzan lo mismo, buscan lo mismo y saben lo mismo (...) En un mundo de cosas finitas, en la que todo es límite y evidencia de otro límite, — la ciencia y el arte— buscan acceder al conocimiento y la experiencia de lo infinito y lo ilimitado.
\end{abstract}

Que una misma imagen resuene en tantas personas, medios y formas, da cuenta de la potencialidad de las imágenes visuales como herramienta comunicativa. El agujero negro era un hecho teórico y una imagen mental, pero tener una prueba materializada fue lo que impactó al mundo. Poole (1997) acude al término "mundo de imágenes" para ubicar a la naturaleza material y social de la visión y la representación. La autora menciona que las formas en las que vemos y representamos al mundo determina cómo actuamos frente a este. El acto que se supone individual de ver, y el acto social de la representación, "ocurren en redes históricamente específicas de relaciones sociales" (p. 4). La imagen del agujero negro no fue un hecho fortuito, por el contrario, toda una teoría física, un grupo de investigadores, técnicas y herramientas específicas fueron necesarias para su reconstrucción. Una representación visual para el mundo de lo que pocos entendían a cabalidad desde la teoría. Para Rappaport (1995) "la historia no es lo que realmente pasó, sino las posibilidades que brinda el futuro" (p. 86). Los agujeros negros eran un hecho del pasado que esperaba ser probado en un futuro, un hecho que se mantenía en el tiempo pero que necesitaba corporificarse y para hacerlo, una imagen visual fue la herramienta predilecta. Conocimos en un presente (que ahora es pasado) una imagen del pasado (como toda imagen del universo) que nos hablaba sobre el pasado, pero también sobre el futuro.

Los tiempos de las imágenes son volátiles como los elementos que limitan el horizonte de sucesos. Las imágenes se suponen estáticas en el tiempo, escapan de lo efímero al tener un cuerpo concreto. Sin embargo, la interpretación de ellas es lo maleable, lo entendible y lo que puede contextualizarse. Esta interpretación puede ser entendida desde el concepto de marcos de Butler (2010), para la autora un marco puede tener tres sentidos: una 
interpretación, una manipulación y una evasión. En primera instancia, el marco comenta la obra, como una suerte de exégesis de la obra. En segundo lugar, el marco puede inculpar o incriminar, y, en tercer lugar, el marco también evade porque uno debe alejarse para contemplar y "enfocar" la imagen. Lo interesante de las imágenes visuales es que estos marcos pueden ser diferenciales dependiendo de quién, dónde y cuándo se esté "enmarcado" la imagen.

La imagen del agujero negro retrató lo infinito y lo ilimitado. Entre millones de imágenes creadas a partir de los pequeños fragmentos retratados, una sola imagen fue la elegida para que el mundo le diera un cuerpo material a lo que la física había descrito desde fórmulas y teorías. Los científicos seleccionaron una entre miles; esto lo sabemos por las declaraciones que han dado de este suceso, pero también podemos verlo con nuestros ojos. La imagen que se supone es la primera (Imagen 2) y que aparece en la pantalla de Bouman, es distinta a la que decidieron hacer pública, y que dieron a conocer como la imagen del agujero negro. La imagen de la pantalla de Bouman no tiene esa parábola brillante en su base como sí la tiene la imagen que se hizo viral (Imagen 1). En la pantalla del portátil —el marco de esta imagen - se ven tres fragmentos brillantes, pero no un continuo que resalta a simple vista. ¿Cuáles fueron los criterios para decidir una entre todas las posibles imágenes? Los científicos argumentan que la decisión se basó en lo que los algoritmos arrojaron como más probable, pero ¿es realmente una cuestión netamente de probabilidad? ¿ningún criterio estético por más mínimo que fuera entró a ser parte de la elección?

Jean-Pierre Luminet fue la primera persona en realizar el cálculo preciso para darle un aspecto visual al agujero negro, y en 1979 publicó una fotografía simulada de este (Imagen 3). Luminet menciona en su artículo que su imagen "podría representar muchas fuentes relativamente débiles, como por ejemplo el agujero negro supermasivo cuya existencia en el núcleo de M87 ha sido sugerida recientemente" (Luminet, 1979: 235). En 1979, Luminet hizo referencia al mismo agujero negro que 40 años más tarde cobró un cuerpo propio y no uno simulado en la pantalla de Bouman (Imagen 2).

Ambas imágenes (Imagen 2-3), son reconstrucciones dadas a partir de cálculos y algoritmos. Una de ellas es una simulación, y la otra es una reconstrucción de millones de imágenes tomadas por medio de un súper telescopio que los científicos lograron construir. Las dos imágenes son representaciones, y ambas son hijas de los tiempos en los que fueron 
creadas. Y es que las imágenes no son reproducciones de una realidad, son acercamientos, desplazamientos, sustituciones, por esta razón podemos fragmentar ambas imágenes, y desplazarnos a través de ellas, descomponerlas, reagruparlas, tratar de entenderlas.

Empecé este ensayo mencionando que concibo a las imágenes más allá de lo visual. Para mí son una evocación que es posible a través de otros estímulos sensoriales. Quise exponer el ejemplo del agujero negro porque reconozco la potencialidad que tiene una imagen visual y por el tránsito entre los tiempos (o la ausencia de ellos) que me permitía hablar de un objeto universal. Rappaport (1995) termina su texto con una cita de Greg Dening sobre como las historias tienen que ser entendidas como "el tiempo desplomado". Así, la imagen del agujero negro al igual que cualquier otra imagen no es un final en sí misma, sino que es "un complejo proceso de hacer la historia". Sin embargo, quisiera concluir problematizando o mejor, poniendo en discusión la importancia y el peso que se les ha dado a las imágenes visuales. Poole (1997) menciona que hacía inicios del S. XIX se generó una economía visual moderna, la cual consta de dos características: en primer lugar, presenta un dominio de la visión el cual está organizado alrededor de la producción y circulación de objetos-imagen y experiencias visuales intercambiables. Y en segunda instancia, el lugar del sujeto observador ha sido rearticulado para adecuarse a ese campo visual móvil y fluido (p.6). La imagen del agujero negro fue viral, y por eso llegó a los ojos de tanta gente, además, es una imagen que en sí misma es potente; el contraste entre el negro absoluto y los colores cálidos llama la atención y genera una aproximación entre el observador y la imagen. El anillo concéntrico que se representa es parte del imaginario común, un referente constante, una figura próxima que es tangible para nosotros, pero, además, es ante todo una imagen visual, una huella de un presente, un futuro y un pasado. Me pregunto entonces si podemos generar un tránsito hacia otras formas de representación de las imágenes con la misma potencia que tienen las imágenes visuales o si las imágenes gestadas a partir de otras fuentes sensoriales no tienen cabida en la actualidad gracias a este presente económico capitalista y, por tanto, económico visual. 
Imagen 1. Primera imagen de un agujero negro ubicado en el centro de la galaxia M87. En la imagen se observa un anillo brillante formado a medida que la luz se dobla en la intensa gravedad alrededor de un agujero negro. Tomada de: https://eventhorizontelescope.org

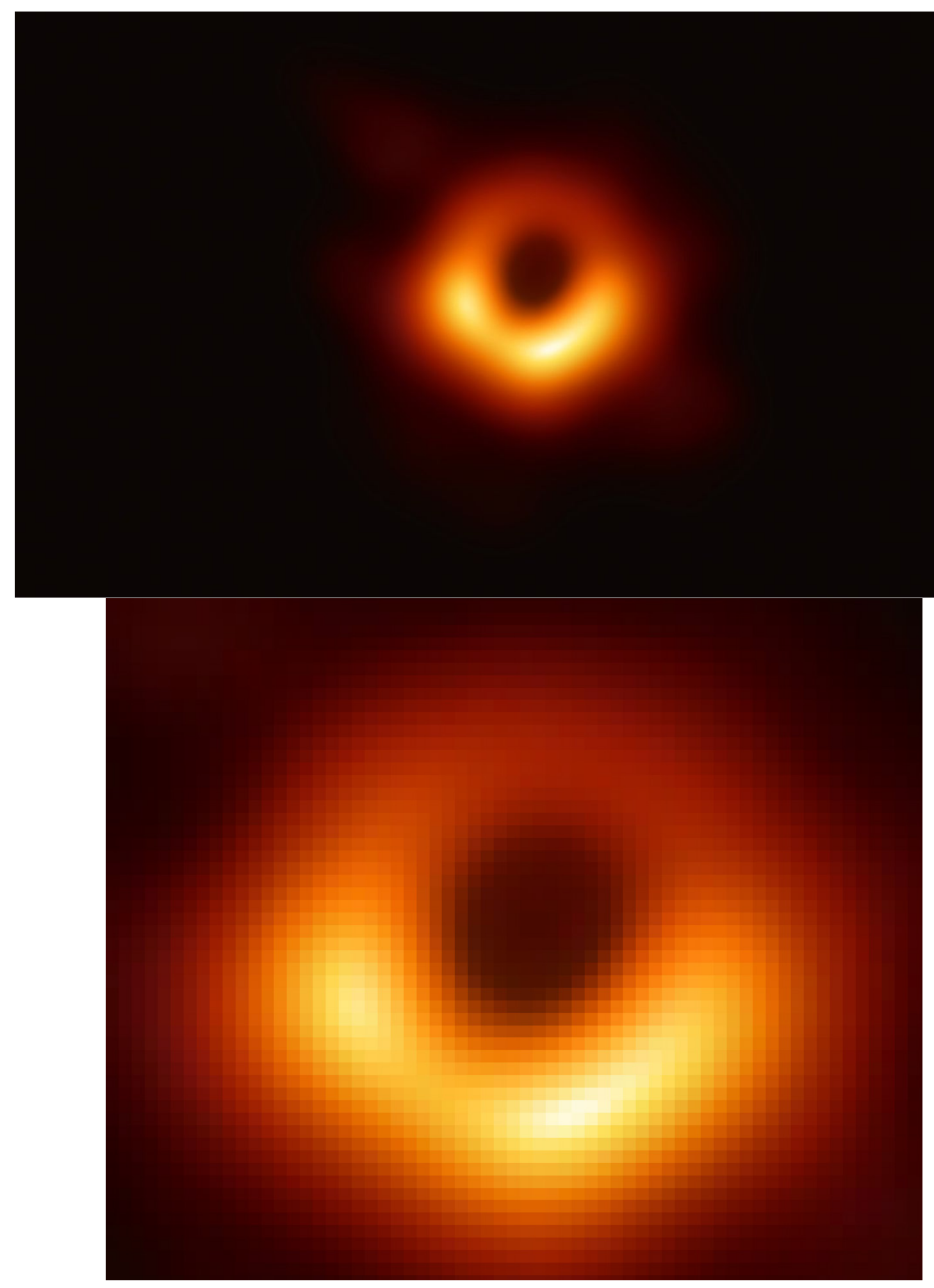

Iluminuras, Porto Alegre, v. 21, n. 53, p. 521-531, agosto, 2020. 


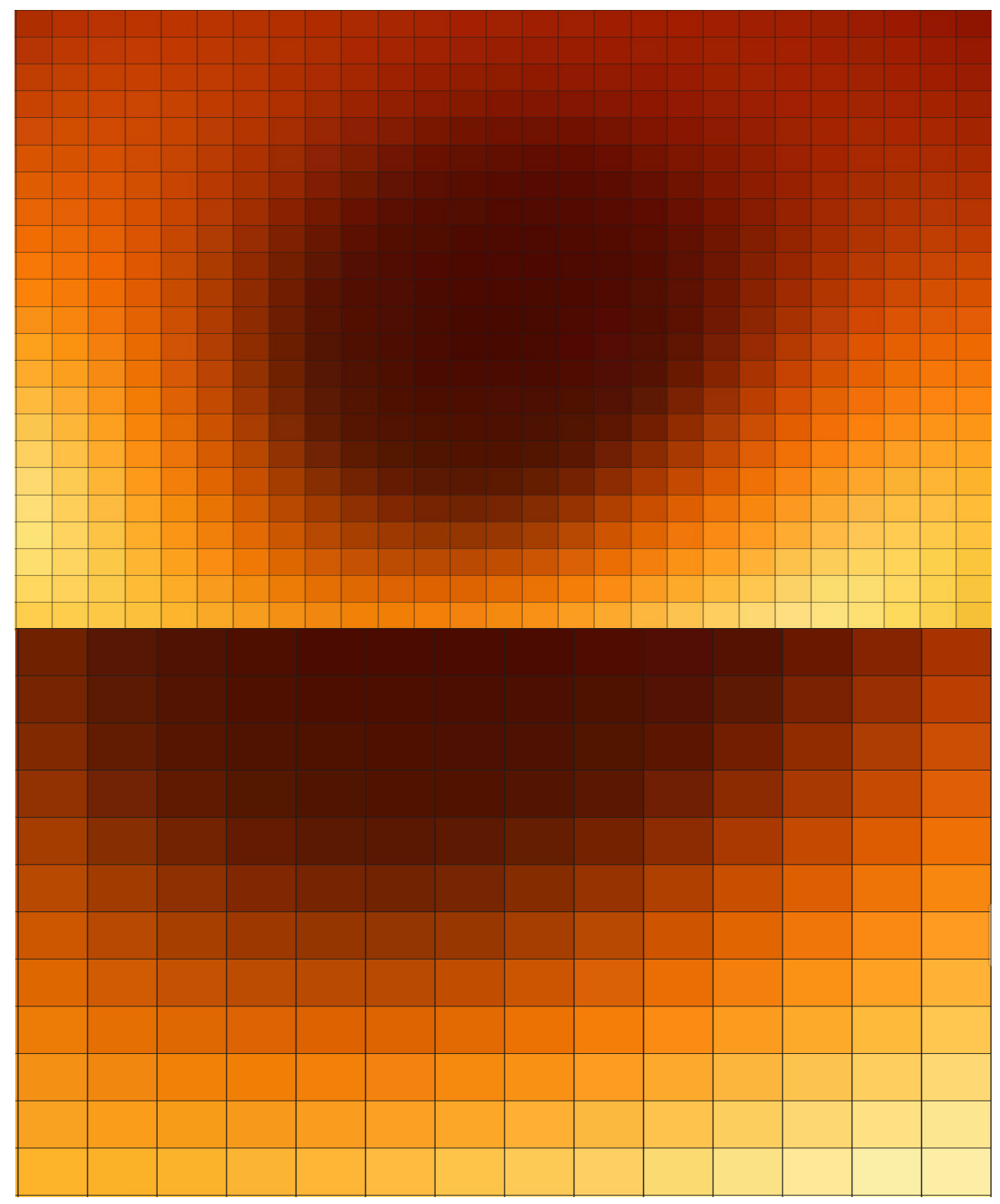




\section{Nelsy Niño-Rodríguez}

Imagen 2. Momento en que se procesó la primera imagen del agujero negro, en la fotografía se encuentra a la científica Katie Bouman quien lideró el desarrollo del algoritmo que hizo posible la reconstrucción de la imagen. Tomado de: https://www.nytimes.com/2019/04/11/science/katie-bouman-black-hole.html?ref=nytes\&mcid=nyt-es\&subid $=$ article

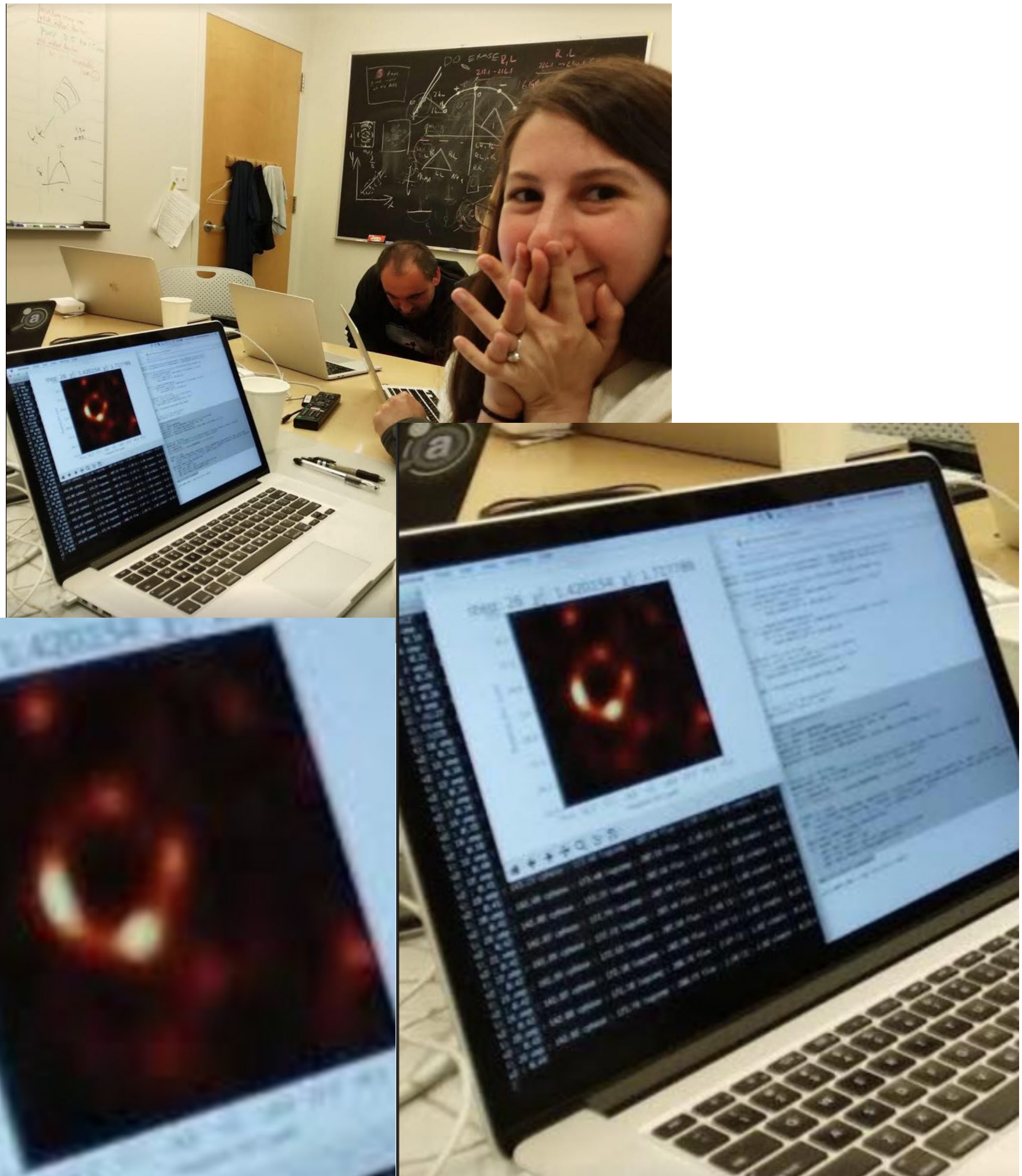

Iluminuras, Porto Alegre, v. 21, n. 53, p. 521-531, agosto, 2020. 
Imagen 3. Fotografía simulada de un agujero negro esférico (Luminet, 1979).

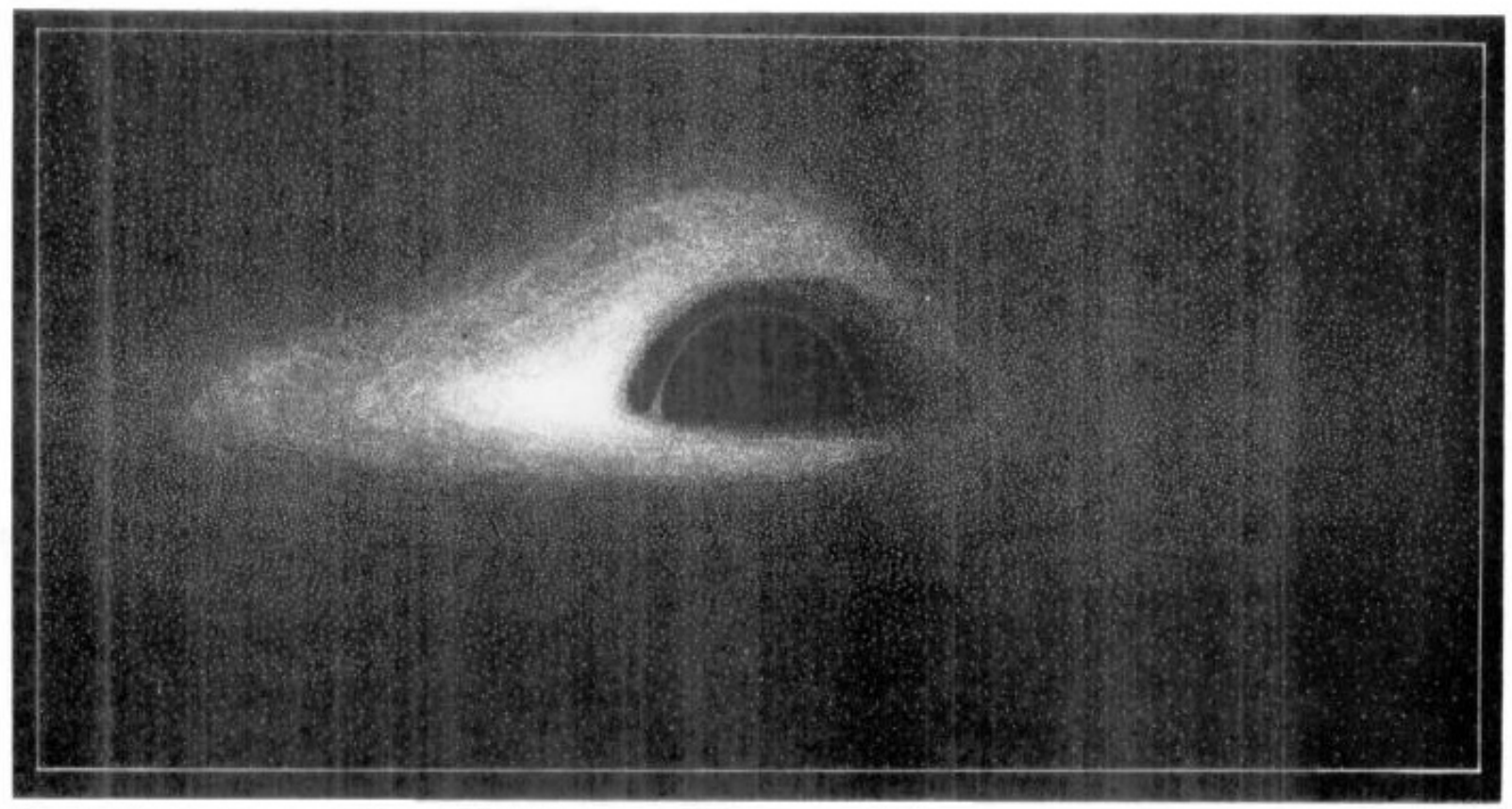

Fig. 11. Simulated photograph of a spherical black hole with thin accretion disk 


\section{REFERENCIAS}

BOUMAN, Katie. "How to take a picture of a black hole" [Video]. Recuperado de: https://www.ted.com/talks/katie bouman_what_does_a black_hole_look_like 2016.

BUTLER, Judith. Capítulo 2. La tortura y la ética de la fotografía: pensar con Sontag. En: Marcos de guerra: las vidas lloradas. México D.F.: Editorial Paidós Mexicana, S. A 2010; pp.95-144.

DOELEMAN, Sheperd. Inside the black hole image that made history [Video]. Recuperado de:

https://www.ted.com/talks/sheperd doeleman inside the black hole image that made hi story. 2019.

LIGHTMAN, Alan. The Accidental Universe. New York: Penguin Random House. 2014.

LUMINET, Jean-Pierre. "Image of a spherical black hole with thin accretion disk". Astronomy and Astrophysics 1979; 75, 228-235.

POOLE, Deborah. Visión, raza y modernidad. Una introducción al mundo andino de las imágenes. Introducción. New Jersey: Princeton University Press. 1997.

RAPPAPORT, Joanne. Palacios de memoria: la etnografía de la historia en el sur de Colombia En: BARONA, Guido y ZULUAGA, Francisco (eds.) Memorias. Primer Seminario internacional de Etnohistoria del norte del Ecuador y sur de Colombia. Cali y Popayán: Editoriales Universidad del Valle/Universidad del Cauca. (En la Biblioteca o en La Calidad). 1995.

SANÍN, Carolina. SaninPazC. (2019, Abril, 10). [Tweet]. Recuperado de: https://twitter.com/saninpazc/status/1115981781159809024. 2019.

Recebido: $10 / 02 / 2020$

Aprovado: 15/07/2020 